\title{
Geophagy as risk behaviour for gastrointestinal nematode infections among pregnant women attending antenatal clinics in a humid tropical zone of Nigeria.
}

\author{
Njoku Ivoke ${ }^{1}$, Nnenna Ikpor ${ }^{1}$, Obinna Ivoke ${ }^{2}$, Felicia Ekeh ${ }^{1}$, Ngozi Ezenwaji1 ${ }^{1}$, Gregory Odo ${ }^{1}$, \\ Florence Iyaji ${ }^{3}$, Uwakwe Onoja ${ }^{4}$, Joseph Eyo ${ }^{1}$
}

1. University of Nigeria, Department of Zoology and Environmental Biology

2. Jackson State University, Department of Epidemiology and Biostatistics, School of Public Health

3. Kogi State University, Department of Biological Sciences

4. University of Nigeria, Department of Home Science, Nutrition and Dietetics, Faculty of Agriculture

\begin{abstract}
Background: Geophagy is wide spread among pregnant women in Ebonyi State, Nigeria.

Objective: The aim of this study was to assess intestinal nematode infections among geophagous pregnant women in Southern Ebonyi State, Nigeria.

Methods: Pregnant women were aged 17-45 years at gestational ages of $\geq 14$ to 24 weeks on hospital enrolment were sampled. Data on geophagy was collected using structured questionnaire. Gastrointestinal nematode status of the participants was determined by stool analyses. Soil types ingested were examined for intestinal nematode ova / larvae.

Results: The prevalence of geophagy (46.4\%) was associated with socio-demographic characteristics. Ascaris lumbricoides and hookworm were associated with geophagy while Trichuris trichiura and Strongyloides stercoralis had no association. Prevalence of $A$. lumbricoides, T. trichiura and $S$. stercoralis differed significantly $(\mathrm{p}<0.05)$ between geophagous and non-geophagous women. The soil types consumed had eggs / larvae of $A$. lumbricoides and T. trichiura. Geophagy is a risk behaviour directly associated with $A$. lumbricoides, hookworm, T. trichiura, and to a lesser extent $S$. stercoralis infection among pregnant women.

Conclusion: Sensitization and mass education of pregnant women on the dangers of geophagy is needed. Furthermore, deworming of pregnant women should be integrated into the healthcare delivery system of the State.

Keywords: Geophagy, gastrointestinal nematode, pregnant women, humid tropics

DOI: https://dx.doi.org/10.4314/ahs.v17i1.5

Cite as: Ivoke N, Ikpor N, Ivoke O, Ekeh F, Ezenwaji N, Odo G, Iyaji F, Onoja U, Eyo J. Geophagy as risk behaviour for gastrointestinal nematode infections among pregnant women attending antenatal clinics in a bumid tropical zone of Nigeria. Afri Health Sci. 2017;17(1): 24-31. bttps:/ / dx.doi.org/10.4314/ahs.v17i1.5
\end{abstract}

\section{Background}

Geophagy is the purposive ingestion of earth excavated from known and usually uncontaminated sources, and not the consumption of surface soils from residential areas ${ }^{1}$. This behaviour is common among many traditional human societies ${ }^{2,3,4}$ and is widespread among women in sub-Saharan tropical communities ${ }^{5,6,7,8}$. Although geoph-
Corresponding author:
Joseph Eyo,
University of Nigeria,
Department of Zoology and
Environmental Biology
Email: joseph.eyo@unn.edu.ng

agy is usually regarded as a response to physiologic demand during pregnancy, the behaviour is culturally and widely accepted especially among pregnant women globally ${ }^{2,9}$. In many tropical sub-Saharan countries where this behaviour is regarded as a response to obligatory physiologic demand, the prevalence among pregnant women has ranged from 28, 42, 46 and 65\% in Tanzania, Namibia, Ghana and Kenya, respectively ${ }^{5,6,10,11,12,13}$. The health benefits derived from geophagic behaviour continue to be subjects of debate. In the low-income groups, geophagy has been reported to be prevalent among women and children to relieve the pangs of hunger ${ }^{2}$. Wiley and Katz have suggested that the consumption of clay soil serves different functions including relief of gastrointestinal distress at different stages of pregnancy, as well as sup- 
plementing nutrients (especially iron and calcium in the second and third trimesters of pregnancy ${ }^{14}$. Nausea and vomiting experienced by pregnant women are reported to have been reduced on ingestion of clay soil ${ }^{3}$. A range of harmful effects, including geohelminth infection, constipation,intestinal blockage and anaemia have been postulated by researchers ${ }^{15,16}$.

Geophagous behaviour has long been a suspected source of soil-transmitted helminth infections ${ }^{2,3,17}$. The effect of geophagy on pregnant women as a consequence of intestinal nematode infection has not been extensively studied although available information suggests that it is especially common among this category of women ${ }^{7,13}$. A pilot survey conducted in association with Local Government Health Committee had shown that geophagy was widely practiced in Ebonyi State, Nigeria by pregnant women.

General objective: Given the role that soil-transmitted intestinal nematode infections play in exacerbating malnutrition, and the importance of maternal nutrition during pregnancy (especially among pregnant women in rural areas), our research group assessed the relationship between geophagy as a risk factor for the transmission of the orally ingested nematode parasites among pregnant women attending antenatal clinics in a referral hospital of Southern Ebonyi State, Nigeria.

Specific objectives: The specific objectives were to (i) identify the soil types commonly eaten by pregnant women, (ii) associate geophagous pregnant women with gastrointestinal nematode infections and (iii) establish the presence or absence of gastrointestinal nematode eggs/ larvae in the soil types.

\section{Materials and methods \\ Study area}

Ebonyi State, one of the thirty six States of the Federal Republic of Nigeria, lies between the coordinates 50401, $60551 \mathrm{~N}$ and 70301, 80301E. The study Local Government Area (LGA), (Afikpo North), is located between latitudes 50471, $50561 \mathrm{~N}$ and longitude 70501, $70551 \mathrm{E}$. The population of 156,649 lives in a land area of $430 \mathrm{~km}^{2}$ with 1:1.2 ratio of male to female ${ }^{18}$. About $52 \%$ of the women are of childbearing age $(17-49)$ years. Topographically, the land is composed of sharp escarpments in the trough of sharply undulating sandstone ridge in an elevation of $250-350$ metres above sea level ${ }^{19}$.
The soil is dominantly loamy to dark brown clay. The climate is typically tropical with a longer humid rainy season (April - November) and a shorter dry season (November - March). The annual precipitation is between $200 \mathrm{~mm}$ and $220 \mathrm{~mm}$ with mean relative humidity (RH) of $78 \pm$ $71 \%$. The humid climatic environment and the indiscriminate defecation in farms by children and young adults create conditions favourable for the development and transmission of the infective stages of soil-transmitted nematodes. The study area has 6 governments grant-aided and 10 private health facilities including the major antenatal clinic located at Mater Misericordiae hospital in Afikpo. The dominant occupations of the inhabitants are farming and shrimp fishing. Agriculture is carried out in small farm holdings dotted with termite mounds, and rice is cultivated in paddy fields. Reports of a pilot survey conducted in public and private health institutions in parts of Southern Ebonyi state indicated that geophagy and intestinal nematode infections were prevalent among pregnant women, hence Afikpo was ideal for the study of the relationship between geophagy and intestinal nematode burden.

\section{Ethical consideration}

All the study protocols were approved by the Research and Publications Committee of the Department of $\mathrm{Zo}_{\mathrm{o}}$ ology and Environmental Biology, University of Nigeria, Enugu State; Afikpo North Local Government Committee of Health, and the administrator, Mater Misericordiae Hospital, Afikpo, Ebonyi State.

\section{Study design and population}

Prior to the commencement of the study, advocacy visits were made to the LGA chairperson, the coordinator of the development centre and the administrator of the hospital to explain the objectives, expected benefits, potential risks, and to solicit for co-operation of the populace. The hospital-based, cross-sectional study was conducted between January 2012 and July 2012 at Mater Misericordiae hospital Afikpo, Southern Ebonyi State. The hospital serves as a referral centre for the component communities in the LGA. From a sample frame of 1,047 pregnant women in various stages of pregnancy who were attending antenatal clinics, a total of 797 participants (approximately 114 per month) were selected using a table of random numbers. The aims and methods of the study were explained to the women who gave verbal consent before the investigations began. Eligibility criteria were: 
residence in the study area for $\geq 10$ years, gestational age $\geq 14$ weeks and 24 weeks on enrolment, and ability to give sourced information. Exclusion criteria included presence of underlying severe morbidities (for example severe diarrhoea, and/or malaria). Geophagous participants were examined for geohelminth infection at baseline and re-examined 2 and 10 weeks after treatment with albendazole. Using a close-ended structured questionnaire, trained female research assistants (midwives) interviewed the participating women in the native language, Igbo, and also obtained data on socio-demographic, obstetrics and geophagous practice (defined as deliberate eating of earth (soil). Geophagous participants in addition provided samples of the soil type they consumed for analysis.

\section{Parasitological examination}

A single freshly-passed stool sample was collected from each pregnant subject at baseline for analysis. Coded number was used to ensure anonymity of the donors and to facilitate the laboratory procedure. The coded number also tallied with the number on the questionnaire of each subject. Stool specimens were examined within an hour for hookworm eggs and on the following day for recovery and identification of other intestinal nematode eggs/larvae using the formalin-ethyl acetate concentration technique ${ }^{20}$.

\section{Types of earth consumed}

The four types of earth usually ingested by pregnant women in the study area were nqu, ukwaka, eja akika and eja uno; Nzu is the moulded clay earth harvested by digging about 2 metres below the soil in a particular site. Ukwaka, like nzu is obtained from a specific area of the soil where it is found in layers. Unlike $n q u$, ukwaka is consumed without further treatment. Eja may be obtained from two main sources: eja akika - termite mounds or eja uno - mud blocks from earth walls of houses. Eja akika like ukwaka is ingested by geophagous pregnant women without treatment. A member of the research team accompanied some of the geophagous women who preferentially consumed eja akika to their farms and obtained soil samples from randomly selected termite mounds for analysis.

\section{Examination of soil types}

To determine the role of different soil types ingested by pregnant women in the transmission of intestinal nematodes, the concentration of the eggs/larvae in each soil type provided was evaluated using the method of Young et al. ${ }^{21}$. Briefly, about $20 \mathrm{~g}$ of each soil type was preserved in $10 \%$ formalin within $24 \mathrm{~h}$ of collection. The samples were transported to the Parasitology Research Laboratory, Department of Zoology and Environmental Biology, University of Nigeria, Nsukka, where sample examination was conducted. Entire sample of each soil type was passed through a double layer of $1 \mathrm{~mm}$ steel mesh into a petri dish. Water was then added to the dish and examined using an inverted microscope with a mechanical stage and a $10 \mathrm{x}$ objective. Detected eggs/larvae were confirmed and speciated with a $40 \mathrm{x}$ objective. This technique which has proven to have greater/equal sensitivity to the floatation technique usually employed to examine parasites in soil, is based on the protocol for identifying nematodes in stool samples.

\section{Data analysis}

The association of geophagy with socio-economic, demographic, obstetrics and soil-transmitted nematodes were evaluated. Out of the 1,047 pregnant women enlisted for the study at baseline, information on geophagy was provided by 797 women at baseline. This group constituted the basis for the cross-sectional analysis. Prevalence rates and 95\% confidence intervals (CI) were estimated using binomial regression models with a log link function $^{22}$. Multivariate binomial regression models were used to estimate the adjusted prevalence and 95\% confidence interval.

\section{Results}

\section{Characteristics of the subjects at baseline}

A total of 797 pregnant women out of the 1,047 eligible for the study provided baseline information and stool samples and are included in analysis. The demographic, obstetric and socio-economic characteristics of the study women at baseline are summarized in Table 1. The mean age of the study subjects was $24.8 \pm 6$ years. Women aged $\leq 20$ years constituted $28.6 \%$ of the study group while $37.5 \%$ were in the $21-30$ years age category. Only $7.9 \%$ of the participants were aged $\geq 41$ years. Most 
Table 1: Baseline characteristics of intestinal nematode-infected pregnant women attending antenatal clinies in southern Ebonyi State, Nigeria, $2012(n=797)$

\begin{tabular}{|c|c|c|c|}
\hline Characteristics & Responses & Frequency & Percentage (\%) \\
\hline \multirow[t]{4}{*}{ Age (years) } & $\leq 20$ & 228 & 28.6 \\
\hline & $21-30$ & 299 & 37.5 \\
\hline & $31-40$ & 207 & 26.0 \\
\hline & $\geq 41$ & 63 & 7.9 \\
\hline \multirow[t]{2}{*}{ Marital status } & $\overline{\text { Single }}$ & 74 & 9.3 \\
\hline & Married & 723 & 90.7 \\
\hline \multirow[t]{6}{*}{ Occupation } & Trading & 219 & 27.5 \\
\hline & Farming & 163 & 20.5 \\
\hline & Civil service & 190 & 23.8 \\
\hline & Small business & 200 & 25.1 \\
\hline & Schooling & 18 & 2.2 \\
\hline & Unemployed & 7 & 0.9 \\
\hline \multirow[t]{3}{*}{ Education(years) } & Primary 1-6 & 672 & 84.3 \\
\hline & Secondary 1-6 & 106 & 13.3 \\
\hline & No formal education & 19 & 2.4 \\
\hline \multirow[t]{4}{*}{ Religion } & Christianity & 771 & 96.7 \\
\hline & Moslem & 0 & 0 \\
\hline & Traditionalist & o & 0 \\
\hline & Other religions & 26 & 3.3 \\
\hline \multirow[t]{3}{*}{ Gestational age } & First trimester & 80 & 10.0 \\
\hline & Second trimester & 278 & 34.9 \\
\hline & Third trimester & 437 & 55.1 \\
\hline \multirow[t]{3}{*}{ Parity } & Primigravidae & 327 & 41.0 \\
\hline & Secundigravidae & 120 & 15.1 \\
\hline & Multigravidae & 350 & 43.9 \\
\hline \multirow[t]{2}{*}{ Geophagy } & Yes & 370 & 46.4 \\
\hline & No & 427 & 53.6 \\
\hline \multirow[t]{4}{*}{ Intestinal nematodes } & Ascaris lumbricoides & 416 & 52.2 \\
\hline & Hookworm & 352 & 44.4 \\
\hline & Trichuris trichiura & 17 & 2.1 \\
\hline & $\begin{array}{l}\text { Strongyloides } \\
\text { stercoralis }\end{array}$ & 10 & 1.3 \\
\hline
\end{tabular}

$(90.7 \%)$ were married with varying occupations including trading $(27.5 \%)$, small business $(25.1 \%)$, civil service $(23.8 \%)$, farming $(20.5 \%), 2.2 \%$ were students at enrolment and $0.9 \%$ were not employed.

Majority $(84.3 \%)$ of the subjects had completed 6 years of primary education; $13.3 \%$ had acquired secondary school education and $2.4 \%$ had no formal education. Christianity was the religion of choice for most $(96.7 \%)$ of the participants. More than half $(55.1 \%)$ of the women were in the third trimester of their pregnancy, $34.9 \%$ in the second trimester while $10.0 \%$ were in the first trimester on enrolment. A substantial proportion (43.9\%) of the participants were multiparous, $41.0 \%$ were experiencing their first pregnancy, $15.1 \%$ had two previous pregnancies. On geophagy, less than half $(46.4 \%)$ of the study population reportedly consumed earth during gestation period. Species of intestinal nematode parasites were detected, to varying degrees from all the participants: A. lumbricoides (52.2\%), hookworm (44.4\%) T. trichiura $(2.1 \%)$, and S. stercoralis $(1.3 \%)$. There was no statistically significant prevalence difference in the intestinal nematode infection between geophagous and non-geophagous women at baseline (46.4\% vs. $53.6 \%$ ) respectively (Table
1).

\section{Geophagy and the correlates}

At baseline, the prevalence of geophagy among the study population was $46.4 \%$. On examination of the correlates of geophagy with socio-economic and intestinal nematode factors using univariate model (Table 2), the age of the pregnant women and their educational status had no significant impact on the prevalence of geophagy. Married pregnant women were more likely to procure and consume earth/soil than the unmarried woman. Also participants who were engaged in farming, small business or who were employed in civil service were more prone to geophagy than those in school or the unemployed. Other socio-demographic factors associated with geophagy included increasing gestational age at enrolment and having had two or more prior pregnancies compared with primipara. Infection with the intestinal nematode $A$. lumbricoides was strongly correlated with geophagous behaviour (unadjusted-prevalence ratio $=1.22,95 \%$ confidence interval $(\mathrm{CI})=1.62-2.14 ; \mathrm{P}=003)$. Similarly, hookworm infection was significantly associated with geophagy, (un- 
Table 2: Univariate associations of geophagy with sociodemographic and intestinal nematode factors among pregnant women in Ebonyi State, Nigeria, 2012 (n = 797).

\begin{tabular}{|c|c|c|c|c|}
\hline Variable & Frequency & Geophagy, n(\%) & $\begin{array}{c}\text { Unadjusted } \\
\text { prevalence ratio } \\
(95 \% \text { CI) }\end{array}$ & P value \\
\hline \multicolumn{5}{|l|}{ A. Sociodemographic factors } \\
\hline \multicolumn{5}{|l|}{ Age (years) } \\
\hline$<20$ & 228 & $87(38.2)$ & 1.00 & \\
\hline $21-30$ & 299 & $197(65.9)$ & $0.95(0.63,1.18)$ & 0.60 \\
\hline $31-40$ & 207 & $65(31.4)$ & $0.86(0.61,1.24)$ & 0.32 \\
\hline$\geq 41$ & 63 & $21(33.3)$ & $0.78(0.54,1.16)$ & 0.28 \\
\hline \multicolumn{5}{|l|}{ Gestational age (weeks) } \\
\hline First trimester & 80 & $28(35.0)$ & 1.00 & \\
\hline Second trimester & 278 & $126(45.3)$ & $1.58(1.05,2.25)$ & 0.017 \\
\hline \multirow{2}{*}{\multicolumn{5}{|c|}{ Parity }} \\
\hline & & & & \\
\hline Primigravidae & 327 & $160(48.9)$ & 1.00 & \\
\hline Secundigravidae & 120 & $38(31.7)$ & $1.28(1.01,1.61)$ & 0.026 \\
\hline Multigravidae & 350 & $172(49.1)$ & $1.10(0.81,1.50)$ & 0.451 \\
\hline \multicolumn{5}{|l|}{ Occupation } \\
\hline Trading & 219 & $97(44.3)$ & 1.00 & \\
\hline Farming & 163 & $98(60.1)$ & $0.82(0.62,0.92)$ & 0.037 \\
\hline Civil service & 190 & $73(38.4)$ & $0.68(0.52,0.83)$ & 0.046 \\
\hline Small business & 200 & $100(50.0)$ & $0.74(0.59,0.95)$ & 0.024 \\
\hline Schooling & 18 & $0(00.0)$ & $0.93(0.63,1.16)$ & 0.134 \\
\hline \multirow{2}{*}{\multicolumn{5}{|c|}{ Marital status }} \\
\hline & & & & \\
\hline Single & 74 & $23(31.1)$ & 1.00 & \\
\hline Married & 723 & $347(48.0)$ & $1.45(1.00,2.09)$ & 0.045 \\
\hline \multicolumn{5}{|l|}{ Education } \\
\hline No formal education & 19 & $8(42.1)$ & 1.00 & \\
\hline Primary education & 672 & $322(47.9)$ & $1.17(0.70,1.99)$ & 0.421 \\
\hline Secondary education & 106 & $40(37.7)$ & $0.70(0.42,1.17)$ & 0.212 \\
\hline \multicolumn{5}{|l|}{ B. Intestinal nematode factors } \\
\hline \multicolumn{5}{|l|}{ A. lumbricoides infection } \\
\hline Yes & 416 & $234(56.3)$ & $1.22(1.62,2.14)$ & 0.003 \\
\hline No & 381 & $136(35.7)$ & 1.00 & \\
\hline \multicolumn{5}{|l|}{ Hookworm infection } \\
\hline Yes & 354 & $127(36.1)$ & $0.98(0.65,2.60)$ & 0.049 \\
\hline No & 443 & $243(54.9)$ & 1.00 & \\
\hline \multicolumn{5}{|l|}{ T. trichiura infection } \\
\hline 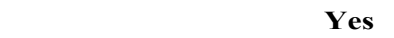 & 17 & $6(35.3)$ & $0.37(0.22,2.60)$ & 0.320 \\
\hline No & 780 & $364(46.7)$ & 1.00 & \\
\hline \multicolumn{5}{|l|}{ S. stercoralis infection } \\
\hline Yes & 10 & $3(30.0)$ & $1.10(0.47,2.51)$ & 0.72 \\
\hline No & 787 & $367(46.6)$ & 1.00 & \\
\hline
\end{tabular}

adjusted-prevalence ratio $=0.98,95 \% \mathrm{CI}=0.65-1.25 ; \mathrm{P}$ $=0.049)$. Other intestinal nematodes detected, T. trichiura, and $S$. stercoralis did not show any association with geophagy (P-values $0.320,0.72$ ) respectively.
As shown in Table 3, 63.24\% of geophagous women were infected with $A$. lumbricoides, $34.05 \%$ with hookworm, $1.62 \%$ with T. trichiura, and $1.08 \%$ with $S$. stercoralis. A. lumbricoides infected a significantly higher proportion $(63.24 \%)$ of geophagous women than non-geophagous

Table 3. Baseline prevalence of intestinal nematode infection among geophagous and non-geophagous pregnant women in Ebonyi State, Nigeria

\begin{tabular}{lcc}
\hline Nematode species & \multicolumn{2}{c}{ Number (\%) } \\
\cline { 2 - 3 } & Geophagousat baseline & Non-geophagous at baseline \\
Ascaris lumbricoides & $(\mathbf{N}=\mathbf{3 7 0})$ & $\mathbf{4 2 7})$ \\
Hookworm & $234(63.24)$ & $122(28.57)$ \\
Trichuris trichiura & $126(34.05)$ & $47(28.10)$ \\
Strongyloides stercoralis & $6(01.62)$ & $4(9.37)$ \\
\hline
\end{tabular}


$(28.57 \%)(\mathrm{p}<0.05) . \quad$ T. trichiura and S. stercoralis infected more non-geophagous than geophagous women. The trend of hookworm infection in both geophagous and non-geophagous women appeared similar (Table 3).

Geophagous women were stratified by type of earth/ soil consumed: $52.4 \%(\mathrm{n}=194)$ of the 370 geophagous subjects preferred eating $n \approx u, 23.5 \%(\mathrm{n}=87)$ preferen- tially consumed eja uno, $10.5 \%(\mathrm{n}=39)$ ate eja akika while $13.5 \%(\mathrm{n}=50)$ ingested ukwaka. The mean soil daily intake by geophagous pregnant women ranged from eja aki$k a(40.0 \pm 6.4 \mathrm{~g})$ to eja uno $(56.2 \pm 5.7)$. The type of soil eaten appeared to impact the nematode parasite infection. Analysis of the $n ₹ u$ revealed the presence of Ascaris and Trichuris eggs in eight of the 24 samples. Similarly, 10 of the 15 eja akika contained Ascaris ova and infective

Table 4. Parasitology of the soil samples ingested by geophagous pregnant women in Ebonyi State, Nigeria

\begin{tabular}{|c|c|c|c|c|c|}
\hline Local soil types & $\begin{array}{c}\text { Number } \\
\text { geophagous } \\
\text { women }\end{array}$ & $\begin{array}{c}\text { Mean } \\
\text { weight(g) of } \\
\text { soil type eaten } \\
\text { daily }\end{array}$ & $\begin{array}{c}\text { Number of } \\
\text { samples } \\
\text { analysed for } \\
\text { nematode } \\
\text { eggs/larvae }\end{array}$ & $\begin{array}{c}\text { Number of } \\
\text { samples with } \\
\text { nematode } \\
\text { eggs/larvae }\end{array}$ & Nematode species \\
\hline $\mathrm{Nzu}$ & $194(52.4)$ & $50.2 \pm 2.9$ & 24 & 3 & $\begin{array}{l}\text { A. lumbricoides(ova) } \\
\text { T. trichiura(ova) }\end{array}$ \\
\hline Ejaakika & $39(10.5)$ & $40.0 \pm 6.4$ & 15 & 10 & $\begin{array}{l}\text { A. lumbricoides(ova) } \\
\text { Hookworm (larvae) } \\
\text { S. stercoralis larvae }\end{array}$ \\
\hline Ejauno & $87(23.5)$ & $56.2 \pm 5.7$ & 25 & 6 & $\begin{array}{l}\text { A. lumbricoides(ova) } \\
\text { T. trichiura(ova) }\end{array}$ \\
\hline Ukwaka & $50(13.5)$ & $53.0 \pm 3.5$ & 6 & 2 & A. lumbricoides(ova) \\
\hline
\end{tabular}

larvae of hookworm and S. stercoralis. Six out of 25 eja uno samples had ova of $T$. trichiura and $A$. lumbriciodes. $A$. lumbriciodes eggs were detected in two out of six samples of ukwaka (Table 4).

\section{Discussion}

The results of our present cross-sectional study showed that $46.4 \%$ of pregnant women in Southern Ebonyi State, Nigeria who were in attendance at antenatal clinics deliberately and regularly indulged in the habit of soil/ earth consumption. The geophagous prevalence recorded is similar to others reported elsewhere in sub-Saharan Africa ${ }^{10,11,13}$. The results further revealed that although geophagy has been widely regarded as an obligatory response to a physiologic demand during pregnancy", the behaviour is accepted culturally and perceived as a symbol of reproduction and fertility in the study area. However, many participating pregnant women reportedly engaged in geophagy because of either the flavour or taste of the earth/soil while most (92.3\%) ascribed the behaviour as inductive and physiological resulting from their pregnancy. After characterization of socio-demographic correlates of geophagy, marital status and occupation appear to be associated with this soil-eating behaviour. Married pregnant women in the study area ingested earth partly to indicate their own fertility and that of their husbands. In the culturally conservative traditional society of the study area, single but pregnant women tended to suppress their pregnancy largely due to local taboos on pre-marital pregnancies. This could account for the significantly higher prevalence $(p<0.05)$ of geophagy observed among the married pregnant participants over the single but pregnant women.

The observed increase in geophagy prevalence, with increasing gestational age recorded in this study is consistent with results of previous studies elsewhere in sub-Saharan tropical communities ${ }^{6,11,23}$. In the course of the interview, many participants reportedly commenced eating earth early in the first trimester. This induced physiological demand increased with increasing gestational age perhaps as a consequence of increased need for micronutrients for growth of the developing foetus as well as erythropoiesis. The practice of geophagy has been thought to help supplement mineral nutrients and have detoxifying effects ${ }^{24}$. The study also showed that the age of the pregnant woman and the educational standard attained were not associated with the prevalence of geophagy. This result further corroborates the findings of earlier studies that showed no association between age or socio-economic status with the prevalence of geophagous behaviour among pregnant women ${ }^{21,23,25}$. A. lumbricoides and hookworm infections were both significantly associated with geophagy, but no association was established between geophagy and T. trichiura or S. stercoralis. In consonant with results of previous studies ${ }^{13,23}$ our present data, found that geophagy was associated with $A$. lumbricoides, T. trichiura and hookworm infections among pregnant women. Association of $A$. lumbricoides with geophagy was also recorded among school children in Kenya, Guinea and South Africa $^{6,9,26}$. However, no association with $A$. lumbricoides, $T$. trichiura, hookworm or $S$. stercoralis infection were record- 
ed in other cross-sectional studies ${ }^{8,21}$.

The positive association of $A$. lumbricoides and geophagy is possibly causal because infection by the parasite is mainly by orally ingesting materials contaminated with infective eggs. This investigation also showed that the soil types consumed by the pregnant participants were, in order of preference, n₹u 52.5\%, eja uno $23.5 \%$, ukwaka $13.5 \%$ and eja akika $10.5 \%$. In all soil types, the sucking action of the material was carried out by the women without further processing of the soil. This action further enhanced the transmission potential of each soil with regard to the orally transmitted geo-helminths, especially Ascaris and Trichuris. The soil type most linked to Ascaris, hookworm and Strongyliodes infection in this study was the eja akika. This finding conforms with the results of other studies ${ }^{9,24}$ that reported termite mounds as the earth most associated with Ascaris infection. Indiscriminate defecation by children and young adults in the study area creates conditions for contamination of the soil with $A$. lumbricoides, hookworm eggs/larvae, Trichuris ova and Strongyliodes larvae. Both $A$. lumbricoides and T. trichiura are principally acquired by ingesting infective eggs in contaminated food, or fingers that have been fecally contaminated. While eggs of $A$. lumbricoides can remain viable in soil for several years, ova of $T$. trichiura cannot withstand drying ${ }^{21}$.

There was a significant difference in the prevalence of A. lumbricoides between geophagous and non-geophagous women. This is in agreement with the report of geophagy among lactating and pregnant women in Boudo District, Western Kenya ${ }^{13}$, but contradicts the report on geophagy and associated geo-helminth infection among school children from Northern Kwa Zulu-Natab, South Afri$\mathrm{ca}^{9}$. There were also significant differences in prevalence of infection with $T$. trichiura between geophagous and non-geophagous women, which corroborated the finding on geophagy as a risk factor for geo-helminth infections among Kenyan school children ${ }^{6}$. This is also plausible biologically since the mode of transmission is through ingestion of contaminated objects. There was no significant intestinal nematode prevalence difference between geophagous and non-geophagous women. A possible explanation is that these categories of women are apparently equally exposed and thus acquired the infection in the course of their farming activities in the fields.

The results obtained from the parasitological examination of the women at baseline and the soil analyses appear to support geophagous behaviour as a mode of transmission, to a greater extent, of $A$. lumbricoides, and T. trichiura, and to a lesser extent of hookworm and S. stercoralis. Two-thirds of the soil types analysed contained eggs of gastrointestinal nematodes. This implies that geophagous women in the study area tended to consume soil types contaminated with infective nematode eggs. The findings are in conformity with results in Kenya and Jamaica where soil ingested by children contained helminth ova ${ }^{3,6}$. Responses from interviews showed that geophagous pregnant women were aware of the health implication but were unaware of the possible link of the habit with intestinal nematode infections. As a consequence many subjects never took precautionary measures in the collection and processing of the soil prior to consumption.

\section{Conclusion and recommendations}

This study has shown that geophagy by pregnant women is a common behaviour among pregnant women in southern Ebonyi State, Nigeria. Furthermore, the practice is associated with the risk of $A$. lumbricoides, hookworm, $T$. trichiura and $S$. stercoralis infections among this category of women, as attested to by the detection of the ova of the parasites in both the stool and soil samples. However, more confirmatory studies are required to prospectively examine the causal association between geophagy and intestinal nematodiasis. As soil consumption has been associated substantially with the prevalence of intestinal nematodes among pregnant women in the study area, mass sensitization, mobilization and education on the adverse consequences of the behaviour can play a role in curbing the infection process. In addition, deworming should complement and not replace the more conventional approaches to intestinal nematode prevention such as improvement and provision of sanitary facilities at the community level ${ }^{27}$.

\section{Acknowledgements}

The authors appreciate the Department of Zoology and Environmental Biology, University of Nigeria, Nsukka, for allowing the research team access to facilities in the department. We also thank the pregnant women who participated in the study, for their cooperation; the midwives and nurses, for assisting in recruiting the subjects; the laboratory and administrative staff of Mater Misericordiae hospital, Afikpo, for their invaluable contributions. 


\section{Conflict of interest}

None to declare.

\section{References}

1. Diamond J, Stermer D. Eat dirt. Discov: 1998; 19(2): 70-76.

2. Hunter JM. Geophagy in Africa and the United States: a culture-nutrition hypothesis. Geogr Rev: 1973; 63:170195.

3. Wong MS, Bundy DA, Golden MH. The rate of ingestion of Ascaris lumbricoides and Trichuris tricbiura eggs in soil and its relationship to infection in two children's homes in Jamaica. Trans R Soc Trop Med Hyg: 1991; 85: 89-91.

4. Abraham PW, Parsons JA. Geophagy in the tropics: a literature review. Geogr J:1996; 162: 63-72.

5. Vermeer DE. Geophagy among the Ewe of Ghana. Ethol: 1971; 10: 56-72.

6. Giessler PW, Mwaniki D, Thiong OF, Friis H. Geophagy as a risk factor for geohelminth infections: a longitudinal study among Kenyan school children. Trans $\mathrm{R}$ Soc Trop Med Hyg: 1998; 92: 7-11.

7. Prince RJ, Luoba AI, Adhiambo P, Nguono J, Giessler PW. Geophagy is common among women in Western Kenya. Trans Soc Trop Med Hyg: 1999; 93: 515-516.

8. Shinondo CJ, Mwikuma G. Geophagy as a risk factor for helminth infections in pregnant women in Lusaka, Zambia. Med J Zambia: 2005; 35(2): 48-52.

9. Saathoff E, Olsen A, Kvalsvig JD, Giessler PW. Geophagy and its association with geo-helminth infection in rural school children from Northern Kwa Zulu-Natab South Africa. Trans R Soc Trop Med Hyg: 2002; 96: 485-490. 10. Thomson J. Anaemia in pregnant women in Eastern Caprivi, Namibia. SAMJ: 1997; 87: 1544-1547.

11. Giessler PW, Prince RJ, Levene M, Poda C, Beckerleg SE, Mutemi W, Shulman CE. Perceptions of soil eating and anaemia among pregnant women on the Kenyan coast. Soc Sci Med: 1999; 48: 1069-1079.

12. Antelman G, Msamanga GI, Spiegelman D, Wrassa EJ, Narh R, Hunter D, Fawzi WW. Nutritional factors and infections disease contribute to anaemia among pregnant women with human immunodeficiency virus in Tanzania. J Nutri: 2000; 130: 1750 -1757.

13. Louba AI, Geissler PW, Estambale B, Ouma JH, Magnussen P, Alusala D, Ayah R, Mwaniki D, Friis H. Geophagy among pregnant and lactating women in Boudo District, Western Kenya. Trans R Soc Trop Med Hyg: 2004; 98: 734-741.

14. Wiley AS, Katz SH. Geophagy in pregnancy, a test of a hypothesis. Curr Antbropol 1998; 39: 532-545.

African Health Sciences Vol 17 Issue 1, March, 2017
15. Key TC, Horger EO, Miller JM. Geophagia as a cause of maternal death. Obstet Gynaecol: 1982; 60: 525-526.

16. Rothenberg SJ, Manalo M, Jiang J, Khan F, Cuellar R, Reyes S, Sanchez M, Reynoso B, Aguilar A, Diaz M, Acosta S, Jauregui M, Johnson C. Maternal blood lead level during pregnancy in south central Los Angeles. Arch Environ Healtb: 1999; 54: 151-157.

17. Halsted JA. Geophagia in man: its nature and nutritional effects. Am J Clin Nutr: 1968; 21: 1384-1393.

18. NPC. Details of the breakdown of the national and state provisional population totals of 2005 census. National Population Commission (NPC), Abuja, Nigeria. Fed Gov Nigeria Off Gazette: 2007; 94(24): 8175-8198.

19. Ofomata GEK, Phil-Eze CN. Geographical perspective on environmental problems and management in $\mathrm{Ni}$ geria. Jamoe Enterprises, Enugu, Nigeria: 2001.

20. Ivoke N. Parasitological Techniques In: Inyang NM, Nwosu MO, Ivoke N. (Eds) Manual of Laboratory Techniques in Biology. University of Nigeria Press Limited, Nsukka, Nigeria: 2006.

21. Young SL, Goodman D, Farag TH, Ali SM, Khatib MR, Khalfan SS, Tielsch JM, Stoltzfus RJ. Association of geophagia with Ascaris, Trichuris and hookworm transmission in Zanzibar, Tanzania. Trans R Soc Trop Med Hyg: 2007; 101(8): 766-772.

22. Spiegelman D, Hertzmark E. Easu SAS. Calculations for risk or prevalence ratios and differences. Am J Epidemiol: 2005; 162: 199-200.

23. Kawai K, Saathoff E, Antelman G, Msamanga G, Fawzi WW. Geophagy (soil-eating) in relation to anaemia and helminth infection among HIV-Infected pregnant women inTanzania. Am J Trop Med Hyg: 2009; 80(1): 3643.

24. John T, Duquette M. Detoxification and mineral supplementation as functions of geophagy. Am J Clin Nutr: 1991; 53: 448-456.

25. Louba AI, Geissler PW, Estambale B, Ouma JH, Alusala D, Ayah R, Mwaniki D, Magnussen P, Friis H. Earth eating and re-infection with intestinal helminthes among pregnant and lactating women in western Kenya. Trop Med Int Health: 2005; 10: 220-227.

26. Glickman LT, Camara AO, Glickman NW, McCabe GP. Nematode intestinal parasites of children in rural Guinea, Africa: prevalence and relationship to geophagia. Int J Epidemiol: 1999; 28: 169-174.

27. Savioli L, Bundy D, Tomkins A. Intestinal parasitic infections: a soluble public health problem. Trans $\mathrm{R}$ Soc Trop Med Hyg: 1992; 8: 